culoides ventricosus Newport. Indeed, if it were not for the natural agencies of control the farmer would be either obliged to abandon wheat growing in the states east of the Mississippi River or adopt drastic measures of control.

One of the most promising measures of control of $I$. tritici at present in some of the Eastern States is to plow under wheat stubble as soon after harvest as is possible, prepare a fine seed bed and sow the clover and grass in August or September instead of seeding in the wheat in the spring. The writer does not have sufficient data as yet on this point to make a definite statement but it seems very promising. Liberal applications of commercial fertilizer or well-rotted barnyard manure will enable the plants to largely overcome the injury.

There seems to be little hope for beneficial results from burning the stubble. This was attempted for two winters in Indiana and at no time, when the ground was frozen, could the stubble be burned.

The writer hopes to have the opportunity this winter of making a thorough examination of the types of the various American species and will then describe any new species he may have, after which he will gladly identify Isosoma for anyone for the privilege of using the data and retaining any uniques or a small series of any that may belong to a new species.

President C. Gondon Hewitt:. If there is no discussion, we will proceed to the next paper by Mr. G. A. Dean.

\title{
RESULTS OF TEN YEARS OF EXPERIMENTAL WHEAT SOWING TO ESCAPE THE HESSIAN FLY'
}

By Geo. A. Dean, Entomologist of the Kansas State Agricultural College and Experiment Station

The time that wheat should be sown to escape the fall brood of the Hessian fly and the time that it should be sown to produce the maximum yield are problems that have been and are still receiving much attention from nearly every student of these subjects. In a state like Kansas, producing an enormous wheat crop, that may equal one fifth of the production in the United States, as in 1914, and in a state

1 Contribution from the Entomological Laboratory, Kansas State Agricultural College, No. 23. This paper embodies the results of some of the investigations in the prosecution of project No. 8, Kansas Agricultural Experiment Station. The writer desires to acknowledge the valuable assistance of J. W. McColloch, assistant entomologist, for much of the work and the careful supervision of the field experiments. He also desires to express his appreciation of the valuable services of Prof. C. E. Call and members of his staff in the Department of Agronomy. 

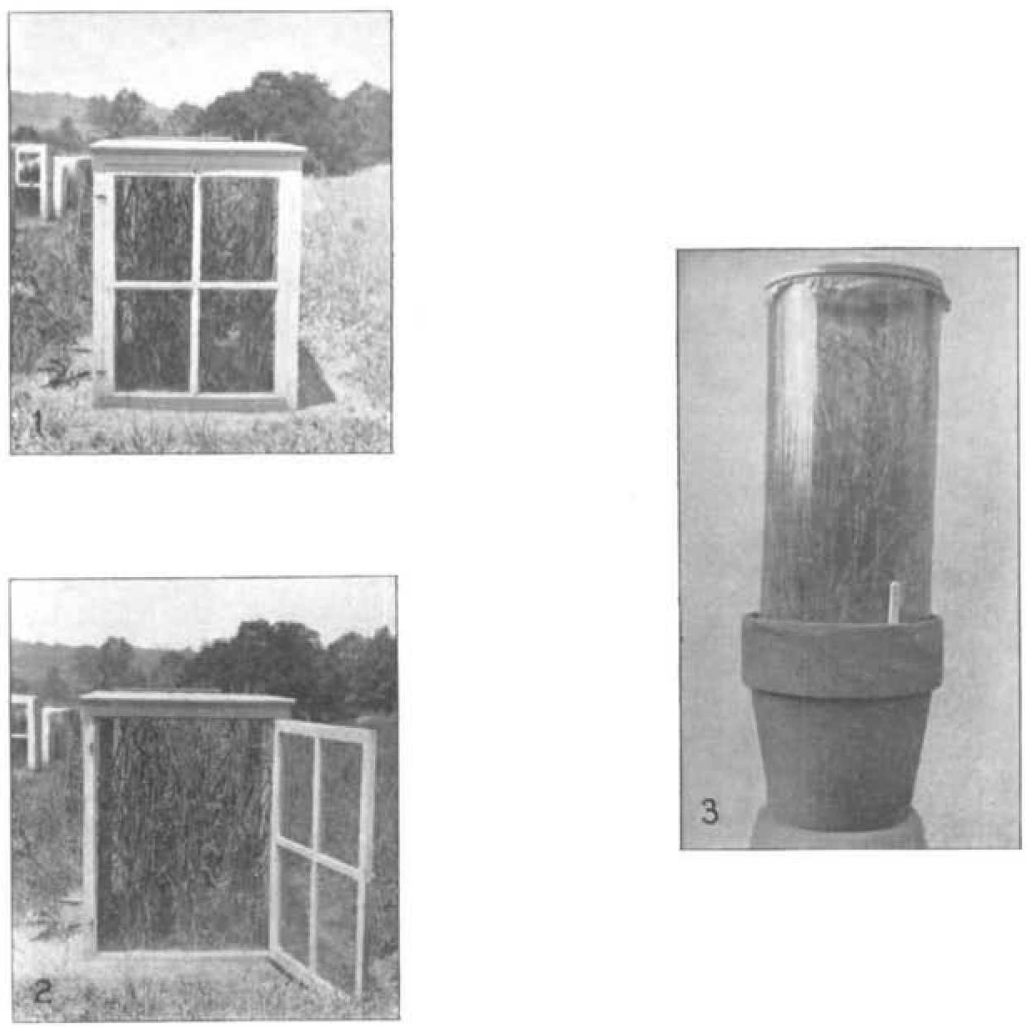

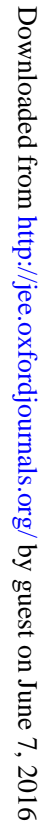

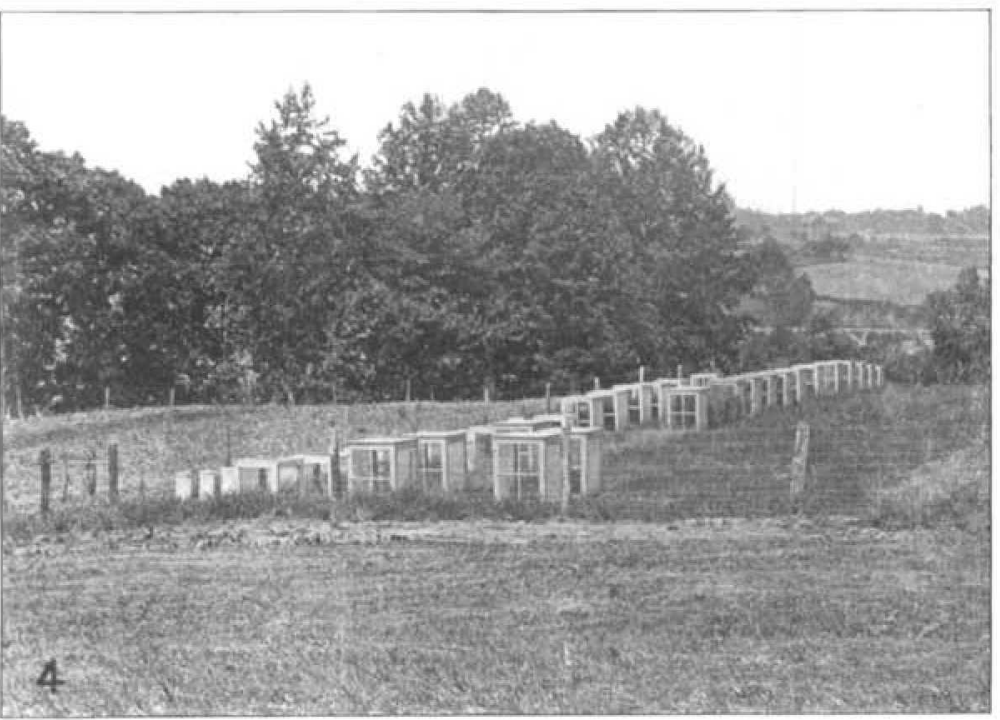



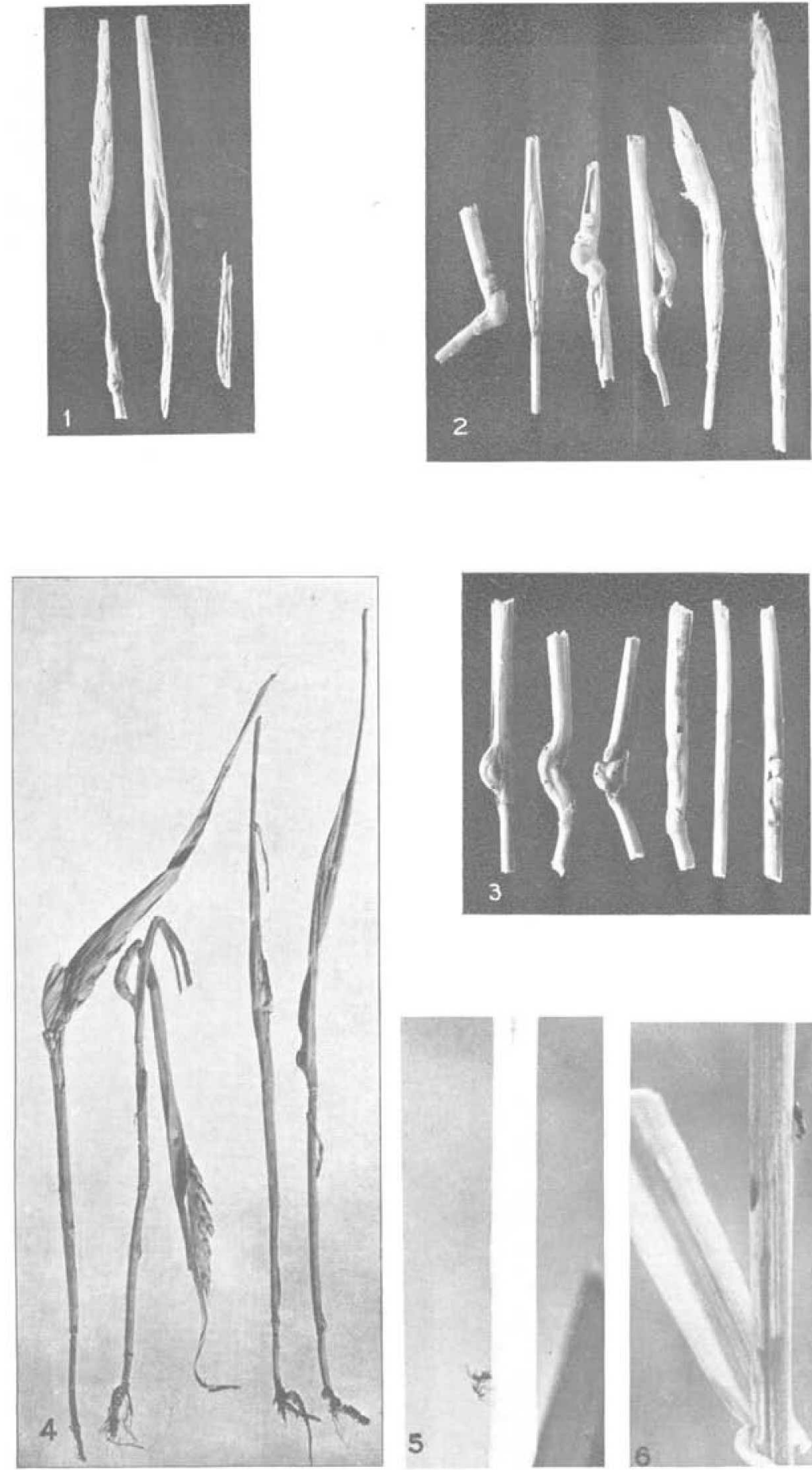

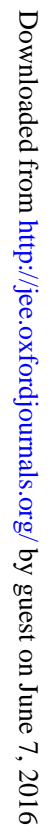
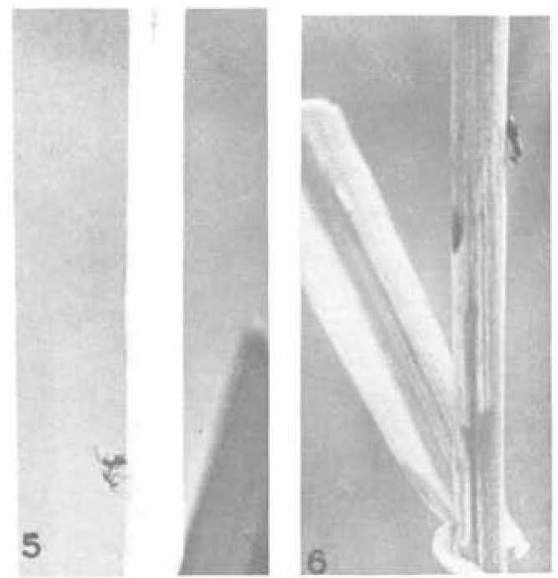
suffering heavy losses from the Hessian fly that may reach sixteen million dollars, as in 1915, the time of seeding to produce the maximum yield and the time of seeding to escape the fly are two of the most important factors in growing wheat.

"There can be no doubt that the seasonal periodicity so characteristic of animals and plants generally is exhibited in both the Hessian fly and its host plants-that there is a period of time in the fall during which, under normal conditions of food supply, the emerging flies have the best possible opportunity to perpetuate their kind and that there is likewise a period during which wheat placed in the soil stands the best chance to produce the maximum yield. This period may be designated as the normal time of fall-brood fly emergence and the normal

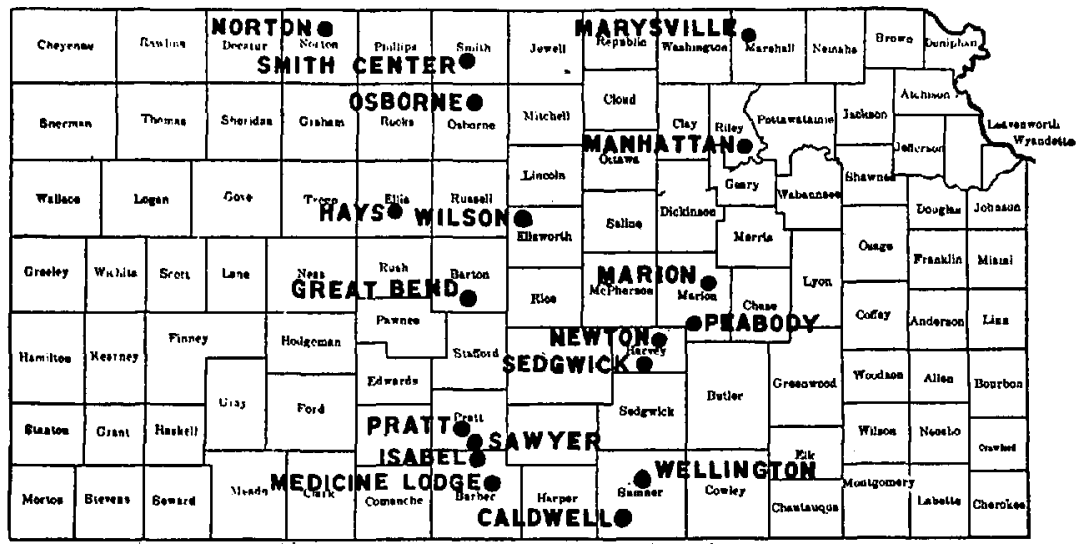

Fig. 5. Map of the state of Kansas showing stations of the last ten years.

time for wheat sowing, respectively. The problem of determining when wheat should be sown to escape the fall brood of the Hessian fly involves the explanation of the relationship existing between the normal period of fly emergence and the normal period of wheat sowing." 1

In order to secure data bearing on the problem, a series of experimental sowing was begun in 1907 by Dr. T. J. Headlee, then entomologist of the Kansas Experiment Station. These sowings have now extended over a period of ten years, and it is planned to continue them over another period of ten years. The sowing in 1907 consisted of a single series of stations extending along the eastern edge of the wheat belt from the northern to the southern part of Kansas, but all subsequent sowings consisted of a double series of stations, one along the eastern and one along the western edge of the great central wheat belt. The individual stations of the eastern series are located from

${ }^{1}$ Headlee, T. J., Journ. Econ. Ent., p. 98, vol. V, No. 2, 1912. 
north to south at Marysvi le, Manhattan, Marion, Peabody, Newton, Sedgwick, Wellington, and Caldwell (Fig. 5) The individual stations of the western series are located from north to south at Norton, Smith Center, Osborne, Hays, Wilson, Pratt, Sawyer, Isabel, and Medicine Lodge. Each sowing consisted of seeding a series of plots at weekly intervals for six or seven weeks, beginning the second week in September. The stations have been secured and managed coöperatively by the departments of Agronomy and Entomology of the Kansas Experiment Station. Representatives of the United States Bureau of Entomology have visited most of the stations each year, taking such data as they desired. In all cases, the ground was prepared, the seed selected and planted, and the crop harvested under the directions of the Department of Agronomy.

In summarizing the data of the experimental wheat sowings, the following conclusions may be had:

(1) Inasmuch as the best time to seed wheat to secure maximum yield varies with different sections of the state, with different seasons, and with other conditions, the proper time of seeding must be determined for each locality by experimental sowing extending over a period of years.

(2) In Northeast Kansas (Table I), the best yield in one year was obtained from seeding September 23 and in the four other years from seeding September 29 to October 11. The experiments show a very clear and definite decrease in the infestation of Hessian fly with late seeding. In one season (1914), about 50 per cent of the wheat sowed before September 20 was infested, while none sowed after the first week in October had any flies.

(3) At Manhattan (Table II), in practically all seasons, the best yields were obtained from seeding during either the fourth week in September or the first week in October. Even in several of the years when very little Hessian fly was present, there was no advantage from early seeding. This is especially true if the ground is well prepared.

(4) In East Central Kansas (Table III), the best yields have been obtained with seeding between September 29 and October 20. In the years of 1914-15 and 1915-16, the wheat sowed early was practically a total loss because of fly.

(5) In Southeast Kansas (Table IV), the sowings seem to favor rather early seeding, that is, from September 15 to September 23, as shown by the results obtained in 1913 and 1914. However, the Hessian fly caused practically no damage in these two seasons. In the seasons of 1914-15 and 1915-16, all plots sowed before October 1 were practically destroyed by the fly, and the late sown wheat produced very smald yields because the fly which infested the early plots mi- 
grated in the spring into the late sown plots and deposited their eggs in large numbers.

(6) In North Central Kansas (Table V), somewhat earlier seeding than for points east and south is desirable. This is because the elevation and latitude shorten the season and grain must be sowed earlier to get a good start before winter. However, the sowing tests show that, if He sian fly is abundant, the seeding should be delayed until the second week in October.

(7) In West Central Kansas (Table Vf), the best yields have been secured from September seedings. Probably the best date for this section, on the average, is from September 15 to September 20. However, as in other sections of the state, if the Hessian fly is present in damaging numbers, the seeding should be delayed until October 1.

(8) In Pratt and Barber Counties (Table VII), the seeding tests. show that where no flies are present, seeding earlier than September15 gives no better yields than somewhat later seeding. When flies are present, later seeding, up to October 1 on poor soil and October 6-7 on fertile soil and a well-prepared seed-bed, will give better results: than early seeding.

(9) In summarizing the time of seeding for the greater part of the wheat belt, it may be said that on an average seed-bed when Hessian. fly is not present in damaging numbers, the maximum yield of wheat will be obtained in an average season by seeding a little earlier than the fly-free date (Table VIII). The better the seed-bed is prepared, the safer it is to wait until the fly-free date to sow. It should be understood that if the Hessian fly is present in damaging numbers and the wheat is seeded earlier than the fly-free date, there is a greater risk of the crop being injured by the fly and, therefore, seeding should be delayed to as near the fly-free date as is practical.

(10) "Wheat that is sowed late usually winter-kills considerably. Since the roots do not penetrate the ground so deeply as when it is sowed early, it is more subject to injury from drought and hot winds. Late sown wheat tillers very little and hence usually gives a thin stand. It ripens later and, in the eastern part of the State, is more likely to be injured by rust than wheat that is sowed somewhat earlier. The quality of late sown wheat is usually not as good as that of early sown wheat.

(11) "If the Hessian fly is present in the neighborhood, wheat that is sowed early is practically certain to be injured by the fly and, in many instances, totally destroyed. In dry seasons, very early seeding is: often detrimental because the heavy growth uses all the moisture stored! in the soil and leaves the crop entirely dependent on seasonal rains. This happens frequently in the western edge of the wheat belt." 1

1 Bul. 213, Kansas Experiment Station, 1916. 
(12) It has been found that early plowing of the stubble, at least five inches deep, is not only very effective in controlling the Hessian fly, but is also very successful in promoting a rapid growth of the wheat in the fall, and for this reason wheat may be sowed considerably later on ground that has been plowed early and deep than if it has been carelessly plowed. "When ground is plowed early, plant food is developed very rapidly and water is usually stored in the soil for the growth of the plant. As a result, growth is rapid, the plants tiller abundantly, and strong roots are developed before winter. Rather late seeding on a well prepared seed-bed will give much better yields than early seeding on poorly prepared ground even when no Hessian flies are present. Also, wheat that has made a good growth is better able to resist attacks of the fly, since it tillers more and there are more stalks to take the place of those destroyed." 1

(13) Since many of the flies migrate considerable distances, early, deep plowing, to be effective, must be practised by the entire neighborhood in such a manner as to include all infested fields, and since it is usually impractical to plow all fields in a neighborhood early and deep, the only way to insure safety from the fall brood of fly is to sow after the fly-free date.

(14) Late sowing alone will protect most of the wheat in the fall from becoming infested by the fall brood of the $\mathrm{fly}$, but it should be remembered that there is also a main spring brood and, if any volunteer is growing in the main field of wheat, or in the old stubble fields left to plant to some other crop the next spring, or if there is a field of early sown wheat nearby, the spring brood of flies, emerging from the infested plants about the first of April, is very apt to infest the late sown crop, and thus wheat absolutely free from fly in the fall may become dangerously infested next spring by the spring brood (Table IX). In Kansas, in the springs of 1915 and 1916, hundreds of cases of this sort were true and it will probably always be true of any year when there is a general infestation over the whole neighborhood. The Hessian flies will migrate in dangerous numbers for several miles, hence the importance of community coöperation cannot be overemphasized. One man with a field of volunteer or with a field of early sown wheat may endanger a number of wheat fields which were free from infestation in the fall.

(15) In Kansas, the important steps in the control of the Hessian fly are: (1) early, deep plowing of the stubble; (2) the proper preparation of the seed-bed; (3) destruction of all volunteer wheat; (4) delay the sowing until the fly-free date; and (5) coöperation.

${ }^{1}$ Bul. 213, Kansas Experiment Station, 1916. 


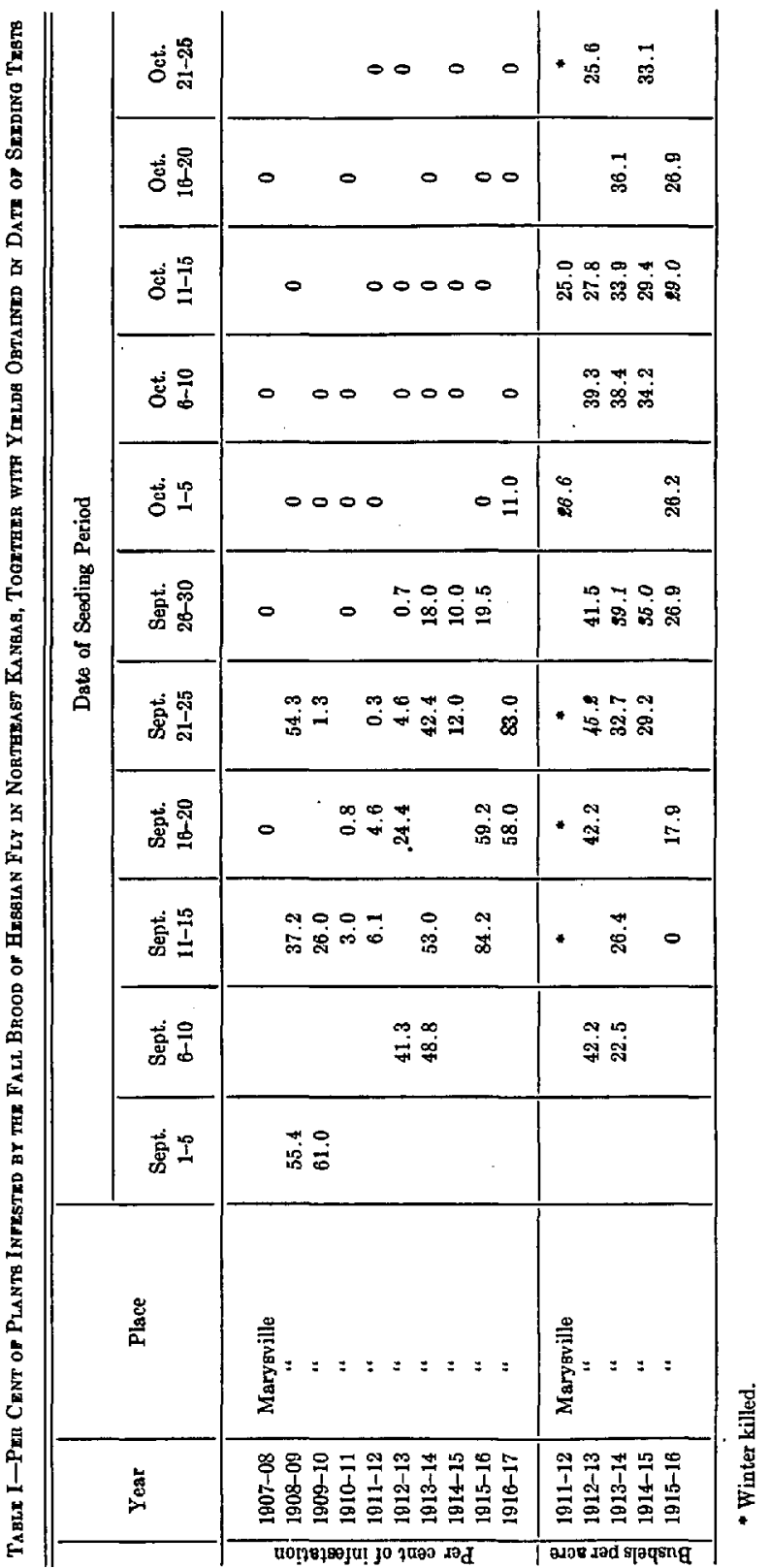




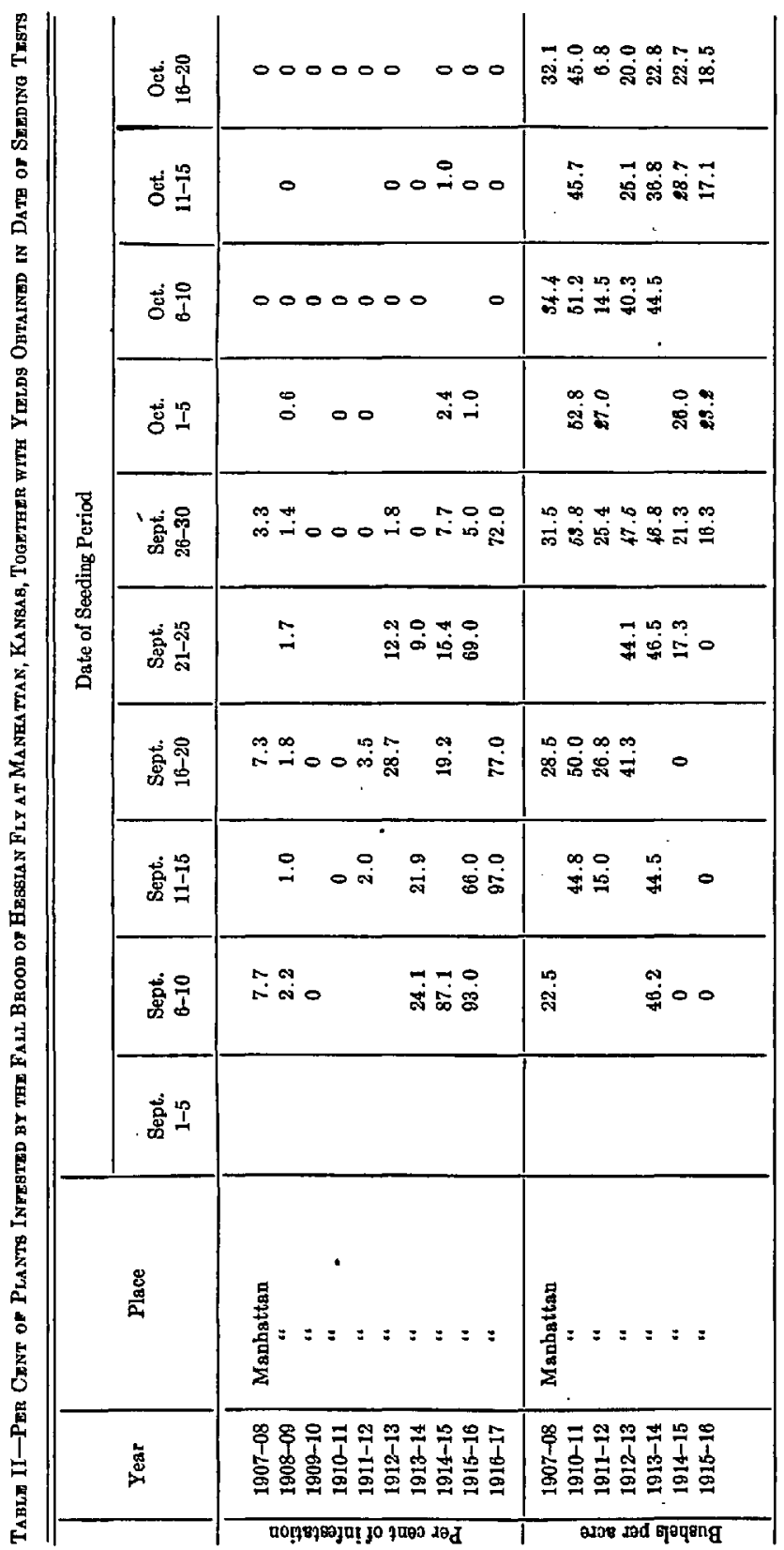




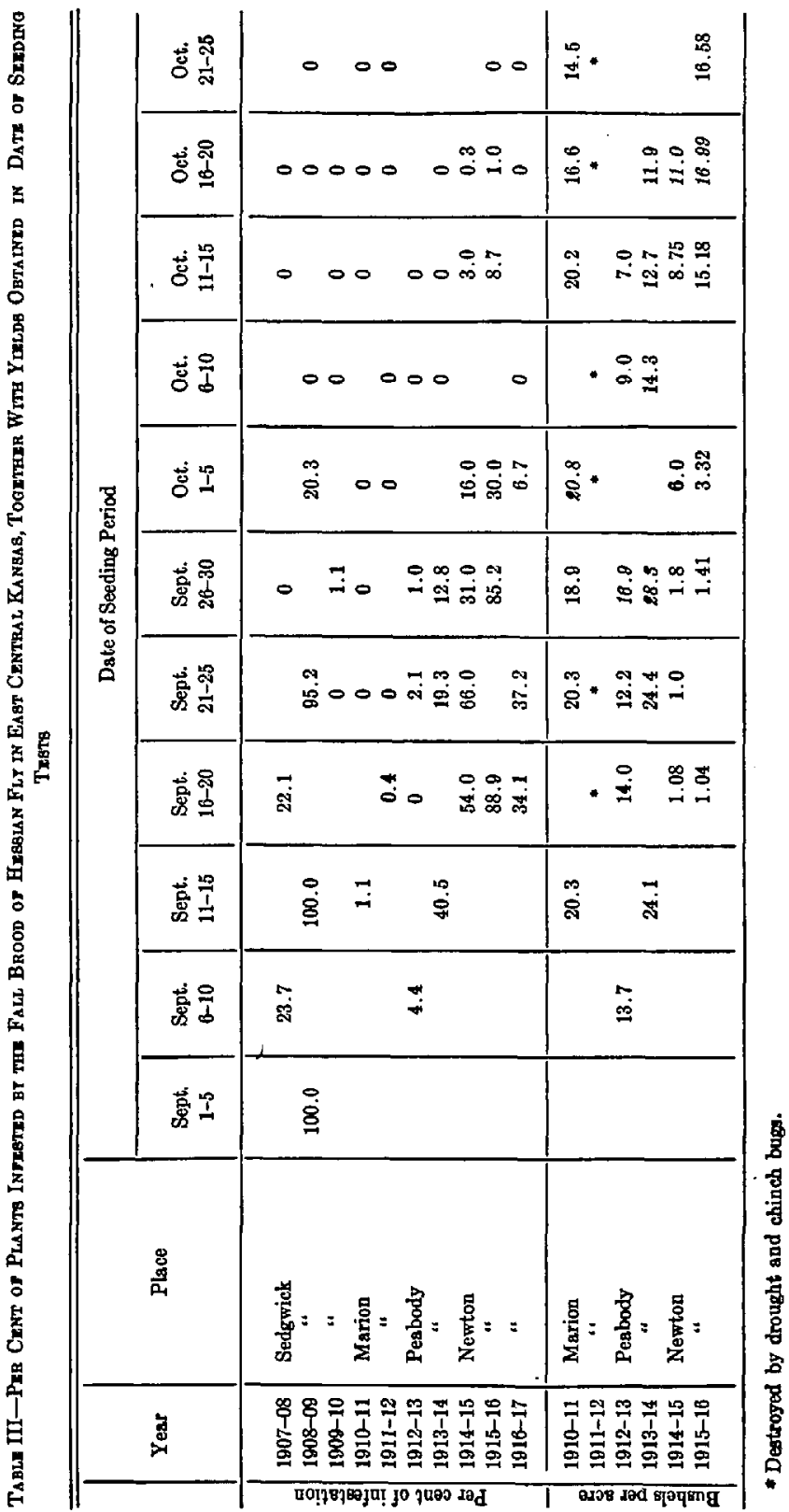




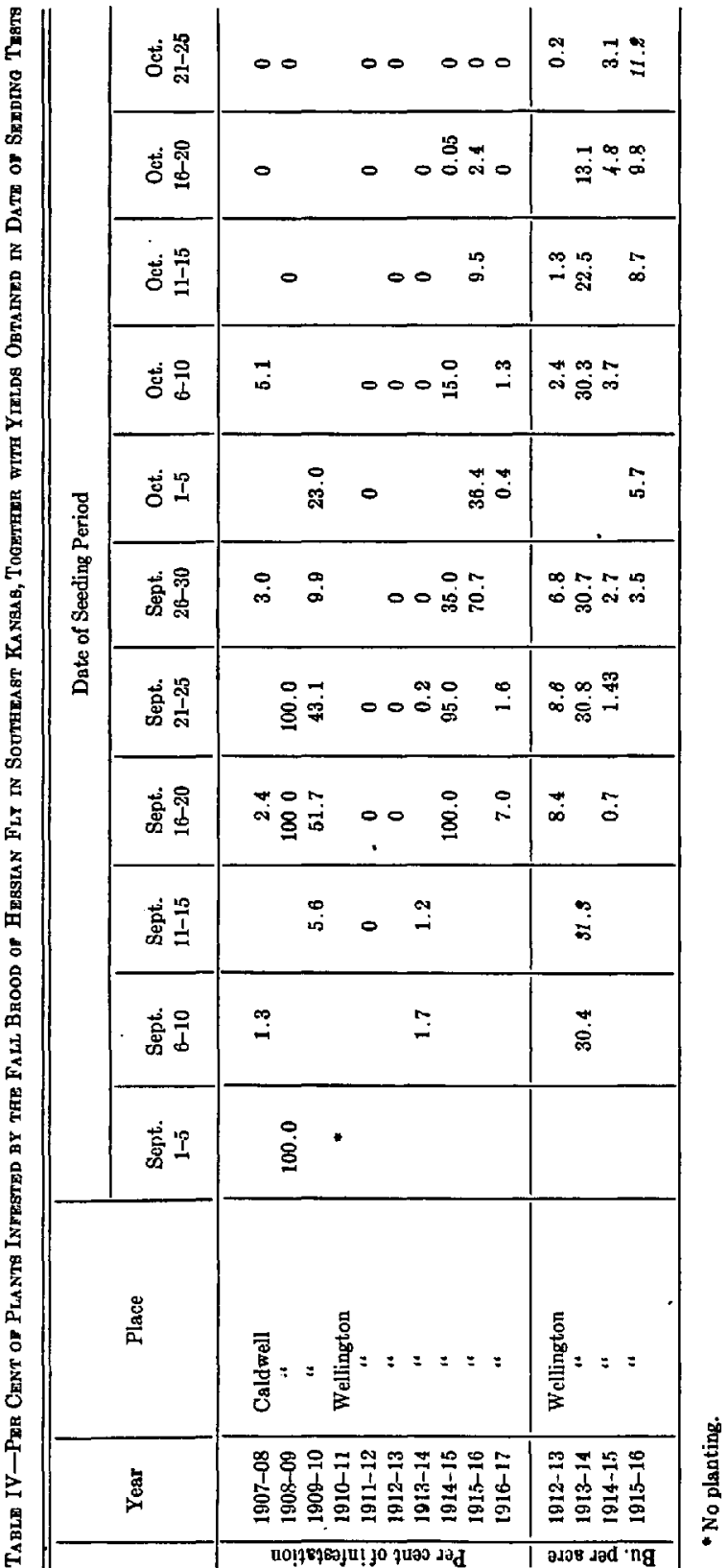




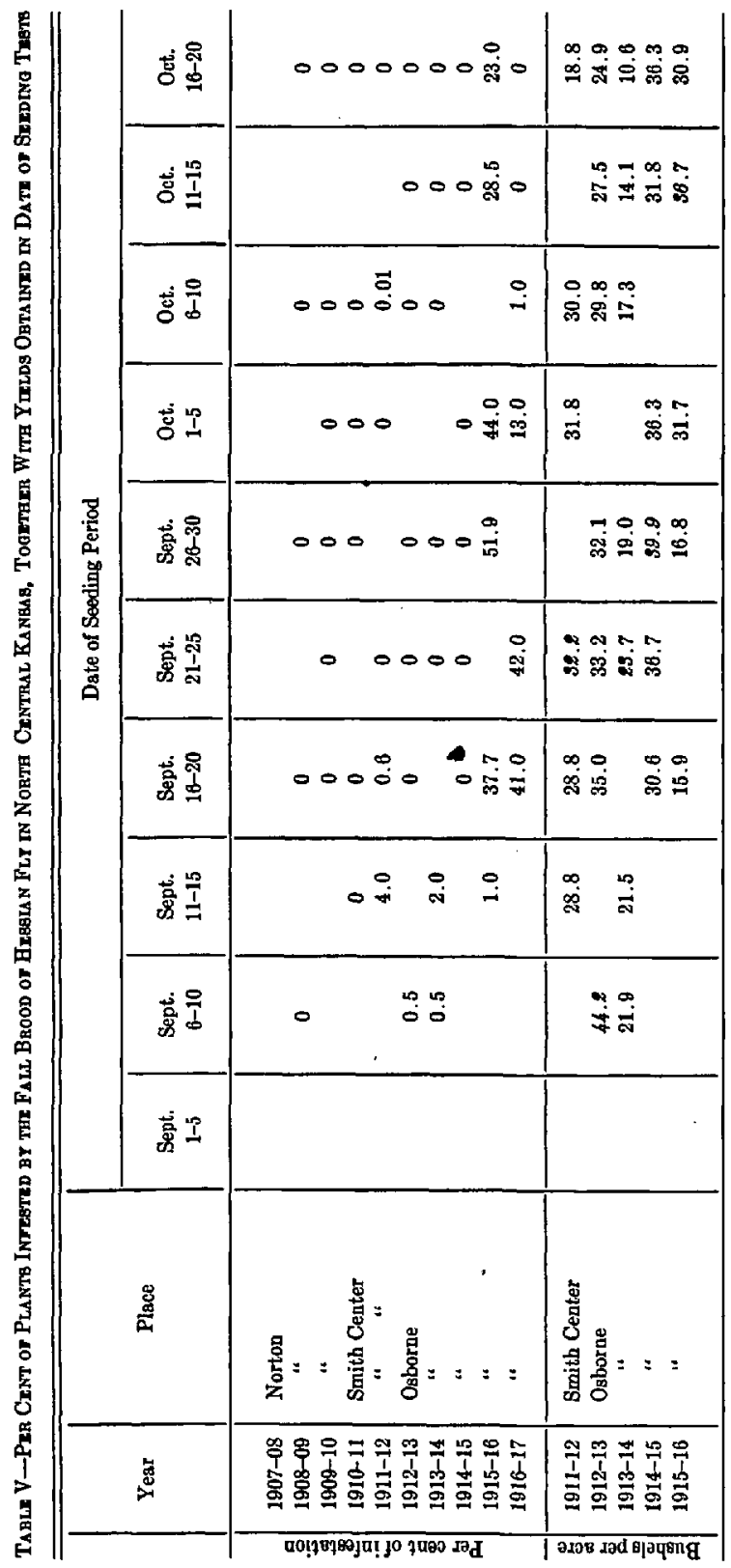




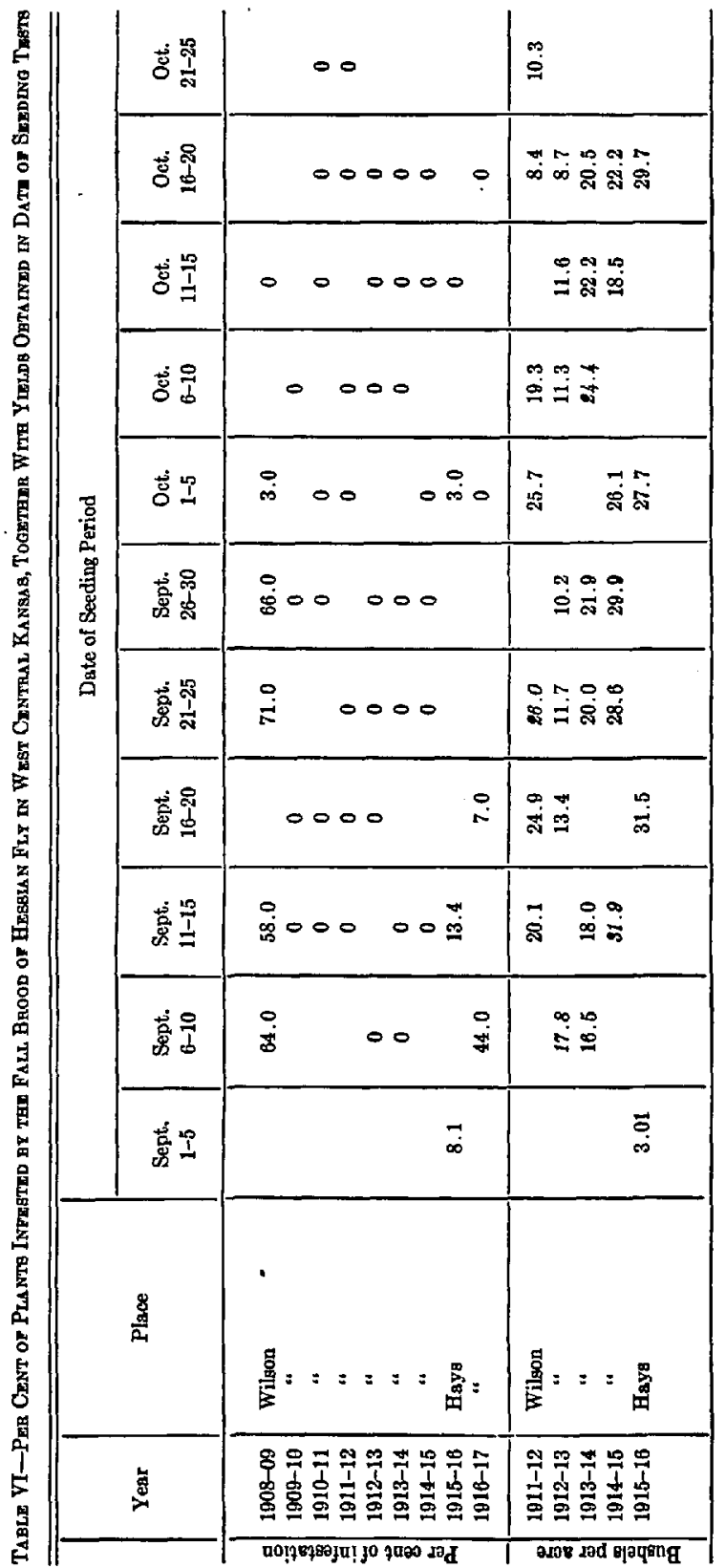




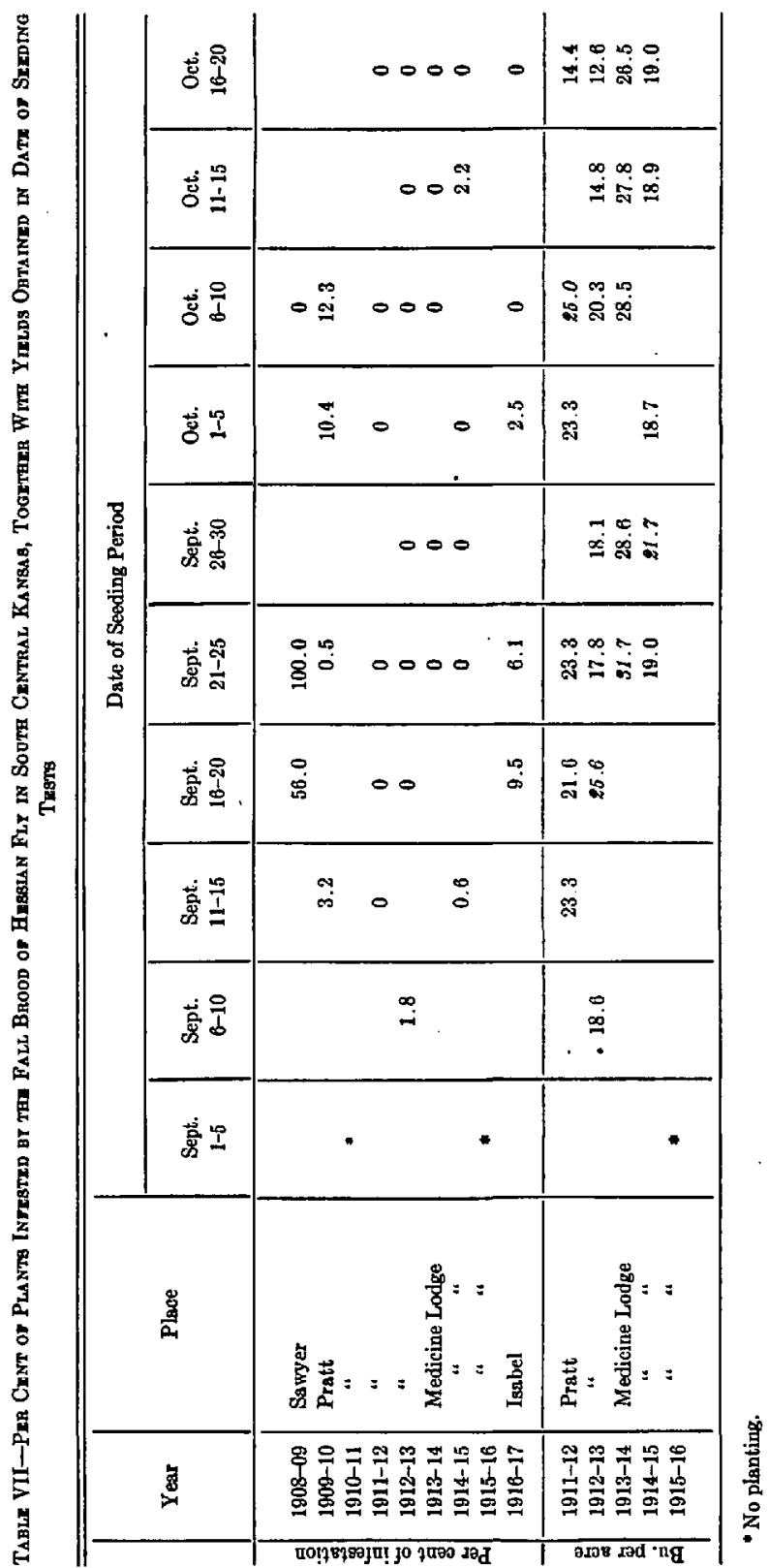




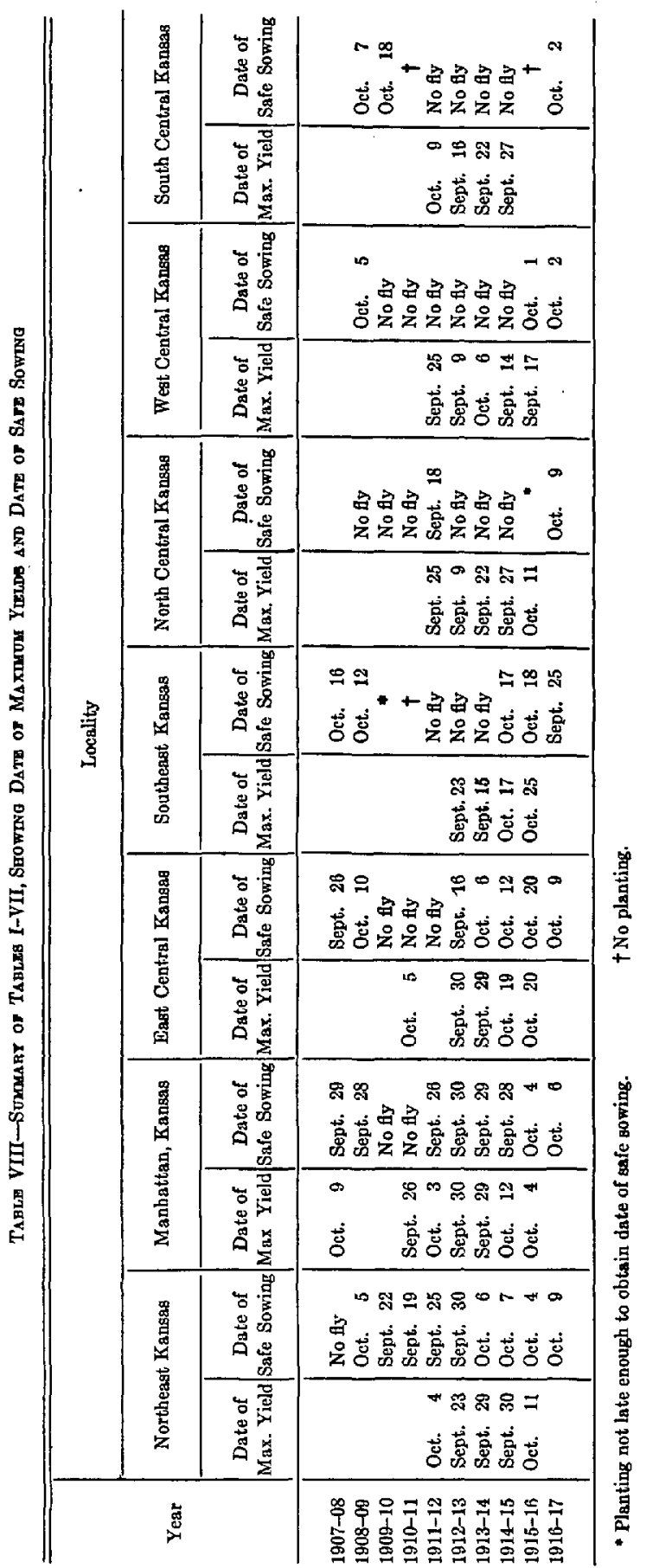


Tabe IX-Per Cent or Immetation on Hessian fut on April 1, 1915, harohn the Spring Brood Had Emerged and Junc 1, 1915, amter thd Spring Brood Had Emrrged at Wrllington and Nrwton

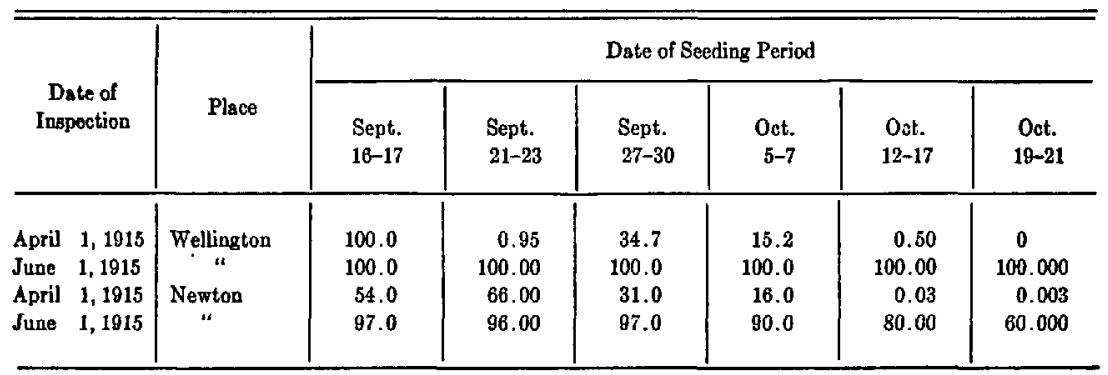

President C. Gordon Hewitt: This paper is now open for discussion.

Mr. T. J. Headlee: I wish to inquire of the speaker how we can harmonize the data derived from the sowings at Columbus and Wooster, Ohio, with the results he has gotton in Kansas since 1912. In five out of a possible six years at Columbus and in seven out of a possible nine years at Wooster, the date of sowing for maximum yield came later than the date of fly-free sowing.

Mr. G. A. DeAn: I cannot explain this, but I believe that in order to get your fly-free date and the date for maximum yield, you must establish these local stations and carry on these experiments covering a number of years. The first two or three years in Manhattan the fly-free date was not far from the time for maximum yield. Then came the years of Hessian fly outbreaks, increasing each year. For instance, the damage in 1915 amounted to fully $\$ 16,000,000$ followed next year with a net loss totaling in the neighborhood of $\$ 15,000,000$ or $\$ 16,000$,000 . It should be remembered that in Kansas we may get five broods of the Hessian fly. For instance, we have the main fall brood, the supplementary fall brood, the main spring brood, the second spring brood, and the summer brood. In a state like Kansas, with a great variation of climate and other conditions, I don't believe you can figure out the conditions from another state, for instance, Ohio, where they do not have such a great variety of climate and conditions as we do in Kansas.

Mr. A. D. Hopkins: This subject of the Hessian fly carries me back to the West Virginia work, so that I am to be pardoned for digressing from forest insects to talk about crop insects. Ever since that work was done in West Virginia, beginning in 1887, I have continued the study of the principle or law of altitude and latitude, and in recent years the factor of longitude has been introduced, which clears up the situation and enables us to indicate dates of periodical events like 
theoretical fly-free dates in Kansas from determined dates in West Virginia or Ohio. Before I came to New York to attend these meetings I attended a conference on the Hessian fly at the Bureau of Entomology and presented maps and tables showing how fly-free dates could be computed for the entire winter wheat region of the United States and Canada, and that the computed or theoretical dates agreed very closely with the general dates for sowing wheat at a number of representative places in each state, as taken from the bulletin on Seed-time and Harvest. ${ }^{1}$ In this bulletin the dates are given on which the greater number of farmers sow wheat, which is a pretty good indication as to the best time to sow wheat to give the best yield in an average season and at the same time be late enough to escape the fall attack of the fly. The computation of fly-free dates was based on Webster's average date for Columbus, Ohio, and our present law of latitude, longitude, and altitude which may be defined as follows:

All other conditions being equal the variation in the date of a periodical event in the seasonal activities of a plant or animal in North America north of Mexico is at the average rate of four days for each $1^{\circ}$ of latitude, $5^{\circ}$ of longitude and 400 feet of altitude-earlier southward, westward and descending in the spring and early summer and later in the reverse directions in late summer and autumn. This gave me a fly-free date of August 31 for Orono, Maine-farthest northand November 11 for southern Texas, a difference of seventy-two days. After determining the theoretical fly-free dates for all of the intervening states, I compared them with the general dates of sowing wheat in the same section of the states and got some rather interesting results, in showing with very few exceptions that the theoretical fly-free date coincided closely with the general wheat sowing periods for all localities compared.

At Wooster, Obio, the fly-free date is September 20 while the average time for sowing wheat is September 18 or two days earlier than the fly-free date. At Columbus, Ohio, the determined average fly-free date is September 25, and the average date of sowing wheat is September 24.

At Wellington, Kansas, the fly-free date should be October 10. Now what is your date, Mr. Dean?

Mr. G. A. Dean: October 12 or 13.

Mr. A. D. Hopkins: The theoretical date misses it only about a day. But October 3 is given as the best date to sow wheat. That agrees pretty well, doesn't it?

Mr. G. A. Dean: Yes, for maximum yields.

Mr. A. D. Hopkins: For Manhattan, Kansas, we have October 5

${ }^{1}$ Covert, James R., Seed-time and Harvest, Bul. 85, Bur. Stan., 1912. 
as the fly-free date and the wheat sowing date October 28. What is your fly-free date for Manhattan?

Mr. G. A. Dean: October 4.

Mr. A. D. Hopkins: Well, there too we miss it only by a day. You cannot calculate across the country much closer. These theoretical dates will approximate the actual dates and thus serve as indices to the proper date for any place in the area in which winter wheat is sown, including Canada. The law of latitude, longitude, and altitude enables us to give an approximate date for sowing wheat anywhere from southern Canada to Texas, and we will be glad to help those of you who are investigating the Hessian fly to apply this law to your local problems. If you will give me the determined fly-free date, latitude, longitude, and altitude for any place in your state, I will explain how to find the theoretical fly-free dates for any other places in the state. Then if you will take these dates as a basis for comparison with previous or subsequent records of actual fly-free dates and let me know later on what you find it will help us both, I think. There is special need of local observations on such details. Here is an opportunity to carry out, on quite an extensive scale, investigations to determine the practical value of the law as applied to the Hessian fly.

With a known date of the disappearance of the fly at the northern range of winter wheat in Canada, we would have from four to seventytwo days in which to inform the farmers in the United States when to sow wheat at places south of the Canadian base. The actual date will vary, of course, in different localities, due to local conditions, but such constant departure will indicate the intensity of the local influence and the number of plus or minus days required to connect the theoretical date. If, on the other hand, it is a seasonal variation, as that resulting from a drought, farmers can be instructed to wait until it rains before sowing wheat.

Mr. T. J. Headles: How does longitude come in? I understand quite well the matter of altitude and latitude, but when you deal with longitude what is the factor? There is a principal factor that you measure, and following that, where do you establish your base line?

Mr. A. D. Hopkins: At any longitude. It makes no difference on what meridian you start. A given periodical event in the spring will be four days later $5^{\circ}$ east and four days earlier $5^{\circ}$ west and the reverse in the fall.

Mr. T. J. Headeee: What is the factor you are measuring?

Mr. A. D. HopknNs: I do not attempt to explain that. I accept the facts as I find them. Specialists in other branches of science will have to explain the controlling factors. The fact that there is a variation due to longitude has been determined in Europe as well as in this 
country. There the variation was found to be nine-tenths of a day to a degree of longitude. ' I have found that for North America it is on the average about eight-tenths of a day to a degree or four days for $5^{\circ}$.

Mr. T. J. HeadLeE: In which direction from the base line?

Mr. A. D. HopkINs: If you begin at any point on any meridian in North America there will be a difference of about four days for each $5^{\circ}$ of longitude, that is, any spring event, controlled by climate, will happen about four days earlier $5^{\circ}$ west of the place and four days later $5^{\circ}$ east of it. Isn't that clear?

Mr. T. J. HeadleE: That's clear; but it seems impossible.

Mr. A. D. Hopkins: We have conclusive proofs on this map, on which it is shown that the lines of equal phenological events, according to the law, are paralleled by the sea level isotherms, the lines of northern limits of wheat, barley and potato culture, tree growth, migration of birds, etc.

(Doctor Hopkins stated that he is preparing a paper on the subject for publication.)

President C. Gordon Hewitt: I will now call upon Mr. Henry Fox to read his paper.

SUMMARY OF INVESTIGATION OF LIGYRUS RUGICEPS DeG.

By Henry Fox, Clarksville, Tenn.

(Withdrawn for publication elsewhere)

President C. Gordon Hewite: The paper is now open for discussion.

Mr. E. N. ConY: I would like to ask Mr. Fox if he has made any survey on the eastern shore of Virginia.

Mr. Henry Fox: I have not been able to do so.

President C. Gordon Hewitt: I will now call upon Mr. J. W. McColloch for his paper.

\section{WIND AS A FACTOR IN THE DISPERSION OF THE HESSIAN FLY ${ }^{1}$}

By JAMEs W. McColloch, Assistant Entomologist, Kansas State Agricultural Experiment Station

In the course of the field experiments on the Hessian fly the writer has had his attention called to many instances of serious infestations

${ }^{1}$ Contribution from the Entomological Laboratory, Kansas State Agricultural College, No. 22. This paper embodies some of the results obtained in the prosecution of project No. 8 of the Kansas Experiment Station. 